\title{
UMA REFLEXÃO SOBRE O CURRÍCULO DE SERVIÇO SOCIAL EM UMA INSTITUIÇÃO DE ENSINO SUPERIOR PRIVADA
}

\author{
A REFLECTION ON THE SOCIAL SERVICE CURRICULUM IN A PRIVATE HIGHER \\ EDUCATION INSTITUTION
}

\author{
Larissa Almeida da Silva ${ }^{1}$ \\ João Paulino da Silva Neto ${ }^{2}$
}

\section{RESUMO}

A presente pesquisa nasceu a partir da atuação profissional em uma IES particular na cidade de Boa Vista. Essa aproximação com o objeto de estudo suscitou o interesse em buscar a literatura referência na área, para então, desenvolver a pesquisa. A partir dessa questão, organizaram-se os objetivos dessa forma: Objetivo geral: Interpretar como o Centro Universitário Estácio da Amazônia proporcionou às suas egressas no Curso de Serviço Social a formação da cultura acadêmica. Objetivos específicos: Conhecer a concepção curricular e o processo formativo no curso de Serviço Social implementado na Instituição de Ensino Superior; indagar dos egressos do curso de serviço social a cultura acadêmica e suas vivências durante a formação; sistematizar as informações para triangulá-las por meio de uma análise da hermenêutica analógica. A pesquisa segue a corrente filosófica hermenêutica analógica, os sujeitos da pesquisa são cinco egressas e uma docente de uma IES particular na cidade de Boa Vista, sob enfoque qualitativo; a entrevista foi usada como instrumento para a coleta de dados e agregar o problema de pesquisa.

Palavras-chave: Formação; Cultura acadêmica; Ensino Superior; Hermenêutica Analógica.

\begin{abstract}
This theme was born from the professional activity in a particular HEI in the city of Boa Vista. This approach to the subject matter generated interest in seeking the reference literature in the area, to then develop the research. From this issue, we organized the objectives this way: General objective: Interpret as Amazon Estacio University Center provided its graduates in Social Work course the formation of specific acadêmica.Como culture: Know the curriculum design and training process in the course of social work implemented in the Institution of Higher education; Inquiring the course graduates of social work on the academic culture and their experiences during training; systematize the information to Triangula them through an analysis of analog hermeneutics. The research follows the current analogical hermeneutic philosophical, the subjects of the research are five graduates and a teacher of a particular HEI in the city of Boa Vista, under qualitative approach, the interview as instrumental used to collect data and aggregate the research problem.
\end{abstract}

Keywords: Formation; Academic culture; Higher education; Analog hermeneutics.

\footnotetext{
${ }^{1}$ Mestranda em Educação - Universidade Estadual de Roraima - UERR, Professora da Universidade Federal do Amazonas - UFAM - almeidalarissa642@gmail.com

${ }^{2}$ Pós-Doutorado em Letras - Universidade Federal de Roraima - UFRR, Professor da Universidade Federal de Roraima - UFRR - profjoaopaulino@gmail.com

Revista Labor Fortaleza/CE, jul/dez 2017 Vol.01, nº 18, p.75-89 ISSN 1983-5000
} 


\section{INTRODUÇÃO}

A presente pesquisa nasceu a partir da atuação profissional no Centro Universitário Estácio da Amazônia na cidade de Boa Vista. Essa aproximação com o objeto de estudo suscitou o interesse em buscar na literatura referência sobre o tema, para então, desenvolver a pesquisa.

Os sujeitos que participaram da pesquisa também são peças fundamentais para a construção da mesma e, com a divulgação dos resultados, os mesmos poderão ter acesso ao debate construído e principalmente, que a partir dela, novas pesquisas surjam e multipliquem essa discussão. Portanto justifica-se a pesquisa pela nova vertente local que ela apresenta, no inédito e desafiador tema proposto e de seus sujeitos envolvidos.

O problema da pesquisa apresenta: Como o Centro Universitário Estácio da Amazônia proporcionou às suas egressas no Curso de Serviço Social a formação da cultura acadêmica. A partir dessa questão, organizou-se os objetivos dessa forma, objetivo geral: Interpretar como o Centro Universitário Estácio da Amazônia proporcionou às suas egressas no Curso de Serviço Social a formação da cultura acadêmica. E específicos: Conhecer a concepção curricular e o processo formativo no curso de Serviço Social implementado na Instituição de Ensino Superior; indagar dos egressos do curso de serviço social a cultura acadêmica e suas vivências durante a formação; sistematizar as informações para triangulá-las através de uma análise da hermenêutica analógica.

A pesquisa segue a corrente filosófica hermenêutica analógica, do autor Maurício Beuchot, o objetivo proposto pela pesquisa, então essa teoria correspondeu às questões expostas.

Como sujeitos da pesquisa apresentam-se cinco egressas e uma docente do Centro Universitário Estácio da Amazônia, sob enfoque qualitativo, utilizando a entrevista como instrumento para a coleta de dados.

O projeto foi organizado pensando em sistematizar as informações. O primeiro capitulo será direcionado ao histórico da profissão de Serviço Social, ensino superior e currículo. O segundo abordará a hermenêutica análgica e cultura acadêmica. E, por fim, os procedimentos metodológicos, expostos através das especificações metodológicas, análise dos dados, apresentando os resultados da pesquisa.

Revista Labor Fortaleza/CE, jul/dez 2017 Vol.01, nº 18, p. 75-89 ISSN 1983-5000 


\title{
Ensino Superior na perspectiva neoliberal: Idas e vindas
}

\author{
Abordaremos sobre o surgimento do ensino superior destacando suas leis, \\ particularidades, avanços e retrocessos.
}

A autora Barreyro (2008, p. 59), aponta que:

\begin{abstract}
Desde a década de 1930, a educação superior brasileira desenvolve-se com importante participação do setor privado: mais de $40 \%$ das matriculas são privadas, desde, pelo menos, 1933. Há um decréscimo em 19640 38\% das matriculas, mas logo depois, a iniciativa privada não-confessional inicia importante processo de expansão incorporando, assim, a classe média surgida do projeto desenvolvimentista, cuja demanda pressionava o sistema.
\end{abstract}

As matriculas no nível superior praticamente dobraram no período de 20 anos, comparando o ano de 1975 somavam pouco mais de 40 milhões, já em 1995 superaram com o quantitativo de 80 milhões de pessoas.

No Brasil, a Lei No. Lei 9.394 de 1996, Art. 43, identifica o seu direcionamento:

I - estimular a criação cultural e o desenvolvimento do espírito científico e do pensamento reflexivo;

II - formar diplomados nas diferentes áreas de conhecimento, aptos para a inserção em setores profissionais e para a participação no desenvolvimento da sociedade brasileira, e colaborar na sua formação contínua;

III - incentivar o trabalho de pesquisa e investigação científica, visando o desenvolvimento da ciência e da tecnologia e da criação e difusão da cultura, e, desse modo, desenvolver o entendimento do homem e do meio em que vive;

A partir disso, a política neoliberal destinará incentivos para a iniciativa privada, com a expansão no acesso de IES em todos o país. Analisa-se, portanto que o número expressivo está em IES particulares, enquanto o Estado diminui o incentivo as IFES, precarizando a qualidade no ensino. O setor de educação privado, tem se fortalecido através de políticas de mercado voltadas para a oferta de bolsas e financiamento pelo FIES a alunos que não ingressam nas IFES:

O setor privado de ensino superior já atingiu uma dimensão respeitável em termos de movimentação de recursos financeiros. Tomando como referência a anuidade média praticada em contratos do FIES (Fundo de Financiamento ao Estudante de Ensino Superior) em 2001 (R\$ 5,4 mil) podemos estimar que somente a receita com alunos de graduação gera um faturamento de 10,3 
bilhões de reais, o que é quase o dobro que o Governo Federal gasta com suas IFES. (ID., p. 180)

Sendo assim, o Estado, pensando em “equilibrar” o seu orçamento, cria saídas que visem à expansão e visibilidade de unidades privadas, eximindo-se então, de sua responsabilidade, já que a Constituição Federal de 1988, em seu Art. 206, assegura que o cidadão tenha acesso gratuito ao nível superior. O ensino público brasileiro é financiado por meio de uma rede de instituições públicas nas quais o ensino é ofertado de forma gratuita. Até os dias de hoje, não se apresenta como um sistema capaz de atender a grande demanda. É um sistema excludente (ROSSO, 2002).

As ofertas de vagas nessas unidades não se restringem apenas à graduação, mais às pós-graduações em nível Lato e Stricto Sensu. Veja que a educação superior no Brasil abarca hoje, um sistema complexo e diversificado de instituições públicas e privadas com diferentes tipos de cursos. (OLIVE, 2002, p. 45).

A seguir será exposto acerca do currículo de Serviço Social.

\section{O Currículo de Serviço Social: Pra quê e para quem?}

O desenvolvimento de estudo nessa área, visão da compreensão dos elementos curriculares e apresenta um grande impasse: Quem queremos formar? A quem está direcionado esse currículo? Qual a concepção desse currículo? Seria um mero executor ou um ser pensante? Quais os interesses que alimentam esses currículos?

Para resgate da historicidade do currículo, entende-se que "[...] há uma tendência, elaboração de currículos, a se seguirem normas, critérios, modelos mundiais, principalmente quando se trata de currículos em âmbito nacional, destinados às massas.” (Saviani, 2010, p. 34).

Já o autor Goodson (2008, p.31), discorre que: “A palavra currículo vem da palavra latina Scurrere, correr, e refere-se ao curso (ou carro de corrida). As implicações etimológicas são que, com isso, o currículo é definido como um curso a ser seguido, ou, mais especificamente apresentado."

No Brasil, “[...]Existiam, no entanto, tradições curriculares fundamentadas em uma base filosófica híbrida que combinava princípios do positivismo de Herbart, de Pestalozzi e dos jesuítas. (MOREIRA, 1995, p. 85). A educação voltada às elites passa a ser questionada a partir da Primeira Guerra. Então, busca-se alfabetizar os trabalhadores assim o sistema educacional período em que a população brasileira apresentava $85 \%$ de analfabetos.

Revista Labor Fortaleza/CE, jul/dez 2017 Vol. 01, n 18, p. 75-89 ISSN 1983-5000 
Em consequência, as reformas educacionais chegaram em alguns Estados brasileiros; São Paulo, por exemplo, tentou erradicar o analfabetismo, através de Antônio de Sampaio Dória, com a obrigatoriedade de dois anos de escolarização do ensino primário. Outro Estado foi a Bahia, a partir de Anísio Teixeira, com o objetivo de capacitar indivíduos a viver em sociedade, com disciplinas escolares com determinados instrumentos e fins. Base teórica essa que contribui para a construção da Escola Nova (MOREIRA, 1995).

A revolução de 30 levou Getúlio Vargas ao poder por quinze anos, sendo assim, um novo modelo econômico surgiu de substituição de importações, desencadeando em tensões. O seu governo foi constituído sob bases populares, levando a um movimento popular, fascista e comunista.

O tópico seguinte identificará a Instituição de Ensino Superior privada, descrevendo a sua trajetória na cidade de Boa Vista, bem como o currículo do Curso de Bacharelado em Serviço Social.

\section{Hermenêutica Analógica}

O presente capítulo pretende apresentar à luz da hermenêutica analógica na Estácio na cidade de Boa Vista, para isso, serão apontados autores que discutem o tema. O estudo proposto visa a uma interpretação a partir da corrente filosófica hermenêutica analógica, teoria inédita em estudos na região Norte do país, elaborada pelo filósofo mexicano Mauricio Beuchot Puente, e a sua proposta pretendem analisar o objeto de estudo trabalhado.

Os estudos sobre a hermenêutica surgiram desde a Bíblia, perpassa pela era Aristotélica, e chega aos tempos atuais:

\footnotetext{
En la hermenéutica analógica, intento recuperar la antigua noción de analogía,que tiene ya larga tradición, pues comienza - filosoficamente hablando - con los pitagóricos, pasa a Pláton, a Aristóteles, atraviesa la Edad Media, disminuye y casi se perde en la modernidad, pero se salva en algunas de sus etapas, como en la barroco y en el romanticismo; por eso requiere ser rescatada en la actualidad. (BEUCHOT; VATTIMO; GÓMEZ,2006,p.16)
}

A interpretação leva o leitor a compreender o fato que está sendo transmitido e levará ao sentido do significado desse texto, podendo ser falado, escrito, de tal forma que possibilite uma interação entre o leitor e o contexto situado. Essa aponta um texto, o seu autor e o leitor. Essa triangulação tenta decifrar o olhar de cada sujeito sobre o objeto investigado. 
A base de sustentação da hermenêutica encontra-se na interpretação de textos, se busca um conceito em que foi produzido ideias e elementos que possam falar as suas intenções: “Además de saber el idioma en el texto está escrito, hay que investigar al autor, su época, su cultura, sus ideias, elementos que nos puedan hablar de sus intenciones textuales." (BEUCHOT, 2014, p. 38)

A hermenêutica de Aristóteles a Quine, dispõe de três modos de significação: “[...] el unívoco, el equívoco y el análogo o analógico. El modo de significación unívoco es el mismo para todos los significados de uno término, como "hombre" se aplica igualmente a todos los seres humanos". (BEUCHOT, 2012, p.14).

“[...] Por otra parte, si entendemos - igualmente con Aristóteles- el arte o la técnica como el conjunto de reglas, que se rigen algo, podemos entender la interpretación como un conjunto de reglas que se va incrementando al paso que la experiencia interpretativa nos enseña [...]". (BEUCHOT, 2015, p. 20).

A hermenêutica analógica se proliferou no racionalismo, empirismo, cientificismos e positivismo. Todavia encontramos isto em alguns âmbitos de filosofia analítica. Ela é herdeira do romantismo por Dilthey que inclui elementos de Schleiermacher e os transmite para Gadamer e Ricoeur e pragmática (herdeira do positivismo). Além de "La hermenéutica unívocas han proliferado en los racionalismos, los empirismos, los cientificismos y positivismos”. (BEUCHOT, 2012, p.17).

A hermenêutica analógica analisa criticamente o entendimento dos textos, além de algumas questões de filosofia do pós-modernismo, nessa crise de epistemologia pós-moderna, ela surge como uma proposta alternativa para leitura da realidade. Assim descreve-se que:

\footnotetext{
En efecto, tenemos, a nivel mundial, una profunda crisis filosófica. Ésta se revela en Europa y los Estados Unidos y, tiene repercusiones en Latinoamérica, sobre todo en México, que tan atento está a copiar las corrientes europeas y estadounidenses.[...]. Pero la europea está más presente, a través de Neitzsche, Heidegger y la hermenéutica, así como antes la havía tenido con el marxismo y el estructuralismo. (BEUCHOT, 2012, p.19)
}

As fases da hermenêutica para a interpretação podem ser por meio da compreensão de fenômenos e depois o estudo de caso, como será realizada nessa pesquisa. O primeiro passo na construção do trabalho aconteceu no levantamento bibliográfico sobre a temática e depois se aprofundou no estudo de caso, após a coleta dos dados. 
O decifrar a realidade está na verdade da obra do autor, que defende: “[...] del texto comprende el significado o la verdad del autor y el significado o la verdad del lector, vive de la ténsion entre ambos, de su dialéctica.Podremos conceder algo más a uno o a outro (al autor o al lector), pero no sacrificar a uno em aras del otro. (BEUCHOT, 2015, p. 29). A criatividade de interpretar, sem importar nenhuma medida proveniente do texto, é a arte de analisar essa realidade a partir da hermenêutica analógica, onde o leitor tem liberdade de decifrar as questões que o texto desafia.

Dessa forma: “[...] una hermenéutica analógica es la más adecuada para esa labor filológica clásica, ya que las principales actividades que conlleva, como la traducción y el comentário, no pueden ser unívocas o completamente exactas, pero tampoco equívocas o arbitrarias". (BEUCHOT ,2011, p.12).

Como exemplo, a relação teoria e prática pode ser analisada a partir da abertura que a hermenêutica permite, pois seu fim principal é levar a praticidade, que o efeito do conhecimento é principalmente teórico, e a expansão encontra-se na aplicação.

\section{Procedimentos Metodológicos}

Desenvolveremos o percurso metodológico da pesquisa, suas particularidades e aspectos, envolvendo os sujeitos, a teoria, tipo de pesquisa, objetivos, universo e amostra, os procedimentos, dentre outros. Como veremos a seguir.

A pesquisa utilizou o método qualitativo, desse modo: "utiliza a coleta de dados sem mediação numérica para descobrir ou aprimorar perguntas de pesquisa no processo de interpretação. (SAMPIERI; CALLADO; LUCIO,2013, p.33

O contexto da pesquisa situa-se a partir de uma inquietação durante a docência no Centro Universitário Estácio da Amazônia (Boa Vista), pelo conhecimento empírico de um fato sobre a formação acadêmica no curso de Bacharelado de Serviço Social.

O momento inicial da pesquisa ocorreu a partir da revisão da literatura, conforme (SAMPIERI; CALLADO; LUCIO,2013, p.76), “implica detectar, consultar e obter a bibliografia (referências) e outros materiais úteis para os propósitos do estudo, dos quais temos de extrair e recompilar a informação relevante e necessária para delimitar nosso problema de pesquisa".

Durante o desenvolvimento da pesquisa foi necessário realizar um levantamento de Leis, Decretos, Portarias, entre outros que sinalizassem a legislação norteadora das ações do 
nível superior no contexto brasileiro. Além disso, o estudo pautou-se na pesquisa bibliográfica que é desenvolvida a partir do material já elaborado, constituído pelos livros e artigos científicos.

A análise de dados no processo qualitativo “[...] recebemos dados não estruturados, e somos nós que damos estrutura a eles". (SAMPIERI; CALLADO; LUCIO,2013, p. 447).

O universo da pesquisa é representado pelas egressas dos anos 2014 e 2015, docentes integrais da Instituição de ensino superior Centro Universitário Estácio da Amazônia. A amostra representada por 01 docente em dedicação exclusiva, regime celetista e cinco egressas. (Apêndice II e III).

Como procedimento, "o estudo de caso, é uma modalidade de estudo amplamente utilizada nas ciências biomédicas e sociais, consiste no estudo profundo e exaustivo de um ou poucos objetos, de maneira que permita seu amplo e detalhado conhecimento". (GIL, 2010, p. 37). A partir do olhar do pesquisador sobre o objeto, sobre o Centro Universitário Estácio da Amazônia, buscando desvelar a formação de uma cultura acadêmica no curso de Bacharelado em Serviço Social.

O estudo de casos em muitos sentidos, teoricamente compatível com as necessidades e recursos do investigador em pequena escala, ou seja, o pesquisador tem liberdade para escolher o objeto e optar os recursos e particularidades de sua investigação (BLAXTER; HUGHES; TIGHT,2004).

Neste tipo de pesquisa, “[...] os dados devem ser coletados e registrados com o necessário rigor e seguindo todos os procedimentos da pesquisa de campo. Devem ser trabalhados, mediante análise rigorosa[...]”. (SEVERINO, 2007, p. 121).

Quanto aos seus objetivos, a pesquisa exploratória, o autor Gil (2002, p. 41), também afirma que "proporciona maior familiaridade com o problema, com vistas de tornar-se explícito e construir hipóteses".

Sobre a abordagem, a presente pesquisa apresentou o enfoque qualitativo, também se guia por áreas ou temas significativos de pesquisa. [...] nos estudos qualitativos é possível desenvolver perguntas e hipóteses antes, durante e depois da coleta e análise dos dados. “(SAMPIERI; CALLADO; LUCIO,2013, p.33).

O diário de campo é um objeto inseparável do pesquisador, pois nele se pode anotar as impressões, os sentimentos, os fatos, curiosidades, histórias, desafios que a pesquisa tem apresentado ao longo dos encontros com os entrevistados. 
Nesse aspecto, a coleta acontece: “[...] nos ambientes naturais e cotidianos dos participantes ou unidades de análise. No caso dos seres humanos em seu dia a dia: como falam, em que acreditam, o que sentem, como pensam, como interagem, etc." (SAMPIERI; CALLADO; LUCIO,2013, p. 417).

O tipo de entrevista escolhido para a pesquisa: “[...]perguntas de estrutura ou estruturais. $\mathrm{O}$ entrevistador pede ao entrevistado uma lista de conceitos como se fosse um conjunto ou categorias." (SAMPIERI; CALLADO; LUCIO,2013, p. 427). Essas designam um roteiro para as perguntas, o que facilita a realização da entrevista, assim não se perde o foco do trabalho a ser desenvolvido.

Como instrumento dessa abordagem, foi utilizado o diário de campo, “também é comum que as anotações sejam registradas no chamado diário de campo pessoal, onde são incluídas: As descrições do ambiente ou contexto, mapas, diagramas, listagens de objetos e artefatos”. (SAMPIERI; CALLADO; LUCIO,2013, p. 392).

A coleta de dados foi realizada a partir de entrevistas focais a mesma é definida como: “[...] uma reunião para conversar e trocar informação entre uma pessoa (o entrevistador) e outra (entrevistados) ou outras (entrevistados)". (SAMPIERI; CALLADO; LUCIO,2013, p. 425).

Apresentarmos o currículo no âmbito do curso de Serviço Social do Centro Universitário Estácio da Amazônia.

\section{O currículo sob o olhar dos sujeitos}

Discutiremos sobre o currículo, o tema foi abordado na entrevista sob diversos aspectos: na visão de egressas e da docente, a sua elaboração e revisão, a relação com a realidade local, além dos desafios para concretização na vida profissional dos acadêmicos.

À luz da teoria hermenêutica analógica, os dados obtidos por meio da entrevista, foi possível realizar a análise do conteúdo sobre a formação de uma cultura acadêmica com os alunos que cursaram Serviço Social.

A docente foi questionada sobre a sua participação na elaboração e/revisão do PPC do curso?

Diante disso, a mesma afirmou que não é possível ser protagonista desse processo, pois não participou, o que dificulta a interação e aproximação do professor na relação ensino e aprendizagem. 
Essa relação é presente quando analisamos todo o contexto em que o sujeito está inserido, ele apresenta fatos históricos, culturais, econômicos, e sua atuação no meio depende desse ciclo que o norteia. Desse modo, “"Hay quienes quieren dar prioridad al lector y entonces hay una lectura más bien subjetivista; hay quienes quieren dar prioridad al autor y entonces hay una lectura más bien objetivista”. (BEUCHOT, 2015, p. 28).

Semelhantemente à questão anterior, sobre a sua participação na elaboração do currículo e discussão sobre o mesmo no âmbito do curso de bacharelado em Serviço Social, a participante afirma que não existe essa abertura visto que o currículo é elaborado no modelo nacional e a alteração ou revisão dele é realizada no Estado do Rio de Janeiro, o que inviabiliza a contribuição local e revisões periódicas.

Portanto, observa-se que o docente gostaria de participar da elaboração e revisões desse currículo, para contribuir com a sua experiência em sala de aula, e as demandas colocadas pelos acadêmicos.

[...] a elaboração do currículo consiste numa seleção de elementos da cultura, passiveis (e desejáveis) de serem ensinados/aprendidos na educação escolar" "[...] como construção social, o currículo resulta de processos conflituosos e de decisões negociadas. [...] há uma tendência, elaboração de currículos, a se seguirem normas, critérios, modelos mundiais, principalmente quando se trata de currículos em âmbito nacional, destinados às massas. (SAVIANI, 2010, p.33,34)

Sobre o conhecimento da realidade local no âmbito do currículo de curso de Bacharelado em Serviço Social, a mesma afirma que não é possível ter essa vivência no curso. E ela, como docente, sugere proposições nessa área: “é necessário a inclusão de disciplinas com conteúdo mais voltados à realidade local, como as questões de fronteiras, terras indígenas, violência sexual, tráfico de pessoas entre outras que contemplem algumas das expressões das questões sociais presentes no Estado.”(Docente, 2016).

A proporcionalidade pode ser levada em consideração no momento de análise, pois a sociedade é dialética ainda que em desequilíbrios, o olhar do interpretador busca esse viés para identificar as questões existentes nesse processo.

Destaca-se que, nos $1^{\circ}$ e $4^{\circ}$ Semestres, o curso ofertava as disciplinas de Fundamentos de Antropologia e Estudos dos Problemas Regionais da Amazônia, nas quais era permitido o debate e aprofundamento sobre as particularidades da região.

Revista Labor Fortaleza/CE, jul/dez 2017 Vol. 01, n 18, p. 75-89 ISSN 1983-5000 
Disciplinas como essas, ofertadas na Matriz Curricular da Atual, oportunizavam aos acadêmicos o conhecimento da cultura local, oferecendo oportunidades para as visitas de campo, nas quais as questões regionais eram visíveis, levando os participantes a ampliarem a visão sobre as particularidades roraimenses.

Temos uma sutileza para interpretar os fatos, analisar minuciosamente a transmissão do autor e entrevistado em determino trecho. Como diz: "La cuestión de la innovación en hermenéutica tiene que ver con la del aumento interno del hábito o la virtud de interpretar”. (BEUCHOT, 2015, p. 78). Dessa forma, o olhar no sujeito passa a ter firmeza e o interpretador conhece o território de sua análise.

As entrevistadas prosseguem com os destaques sobre as disciplinas, TULIPA relata:

$\mathrm{Na}$ disciplina de Antropologia, fizemos uma visita a Casa do Índio-CASAI, e lá a gente pôde ver a cultura indígena, até que o professor fez essa dinâmica conosco, então eu não posso reclamar da grande da Atual, eu era aluna Estácio com grade Atual. E o estágio, é o momento que a gente tem o contato com a sociedade local. (Pesquisa de campo,2016)

Sobre a disciplina que desenvolva esse conhecimento com a realidade local, $50 \%$ afirma que era possível, utilizando-se do componente curricular "Estudo dos problemas regionais da Amazônia". Essa é composição da matriz curricular da Faculdade Atual. No modelo Estácio não é possível visualizar essa disciplina, o que enfraquecerá a formação profissional dos novos acadêmicos. Pois se os mesmos tivessem acesso a essas informações locais, possibilitaria o conhecimento sobre a cultura local.

A presente matriz curricular não apresenta disciplinas obrigatórias voltadas à realidade local, essa é produzida em um sistema nacionalizado, dirigido pelo Rio de Janeiro, em sua central. Uma revisão para essa questão seriam as disciplinas optativas, que possibilitassem às regionais inserirem disciplinas com enfoques locais. Como no caso da matriz Atual apresentada anteriormente.

Desse modo como a Estácio copila os seus currículos, generaliza o conhecimento e o fragmenta, dificultando assim a proximidade dos alunos com o real currículo, um que abarcasse temas do seu cotidiano profissional local. Espera-se que o conhecimento ofertado apresente elementos cotidianos, como aponta: "O currículo é um elemento importante para definir relevância da educação, particularmente por meio de três aspectos, que poderiam ser identificados com suas bases estruturais, disciplinares e cotidianas [...]"(BRASLAVSKY,2004, p.31).

Revista Labor Fortaleza/CE, jul/dez 2017 Vol.01, nº 18, p. 75-89 ISSN 1983-5000 
Sobre as influências que sofrem os currículos em sua formulação, Apple (1989, p. 26), expõe: “[...] e o currículo explícito e o currículo oculto no seu interior - exercem na reprodução de uma ordem social estratificada que continua sendo notavelmente iníqua em termos de classe, gênero e raça." Vemos então, as “mãos invisíveis" por trás da elaboração dos currículos, além do cenário antagônico no que o mesmo é gerado.

Para se construir currículos, é indispensável o conhecimento da profissão e suas relações: econômica, cultural e material, como destaca o autor EAGLETON (2005), a questão da cultura é fortemente apresentada nesse universo. O que nesse caso, não é levado em consideração, porque a questão da cultura estar de fora do contexto curricular. Ou seja, atendendo à demanda roraimense, por meio de disciplinas optativas que ofertassem saberes sobre a cultura local.

Discutiremos sobre a cultura, a visão que as egressas e a docente expõe sobre essa questão.

\section{CONCLUSÃO}

A pesquisa teve por objetivo delinear a leitura sobre a realidade, a fim de problematizar desde a hermenêutica analógica à formação da cultura acadêmica em uma IES particular na cidade de Boa Vista.

O estudo alcançou o objetivo geral proposto, de interpretar como o Centro Universitário Estácio da Amazônia proporcionou às suas egressas no Curso de Serviço Social a formação da cultura acadêmica. A formação da cultura acadêmica, pôde ser analisada por meio da observação durante a coleta de dados, além do relato da vivência durante o processo de formação e essa interpretação realizada por meio da hermenêutica analógica possibilitou a compreensão de como essa se materializava no cotidiano profissional das entrevistadas.

Os caminhos utilizados durante a pesquisa foram os objetivos específicos: Conhecer a concepção curricular e o processo formativo no curso de Serviço Social implementado na Instituição de Ensino Superior; indagar dos egressos do curso de serviço social a cultura acadêmica e suas vivências durante a formação; sistematizar as informações para triangulá-las por meio de uma análise da hermenêutica analógica.

Os passos indicados, ainda no Projeto de Pesquisa e após na concretização (campo), foram realizados com êxito, inicialmente os documentos do curso de Bacharelado em Serviço 
Social foram analisados, o Projeto Político Curricular foi ímpar neste processo, pois nos apresentou dados essenciais na composição inicial da pesquisa.

A pesquisa contribuiu para o crescimento profissional e intelectual, além da minha formação continuada, e o processo de ensino-aprendizagem que o mestrado oferta, nos leva a um conhecimento mais apurado sobre o campo da educação.

Diante do exposto, apresenta-se o resultado da pesquisa de forma simplificada: os dados apontam que 75\% das egressas afirmam que o currículo de Bacharelado de Serviço Social não apresenta proximidade com o conhecimento da realidade local.

O trabalho não se finda por aqui, pois uma pesquisa inicia com novas questões que surgem ao longo do processo. Contudo, apresento então, a partir de uma minuciosa análise, a produção de algumas proposições que as entrevistadas defenderam como consideráveis para mudança do processo de ensino e aprendizagem ofertado pela instituição.

As questões culturais para contextualizar o saber local e o trabalho deste profissional verdadeiramente situado, assim como as disciplinas a serem acrescentadas no currículo do Curso de Bacharelado em Serviço Social sugere como obrigatórias: Elaboração de Projetos Sociais, Estudos Geopolíticos do Estado de Roraima, Cultura Roraimense, Particularidades Sociais do Estado de Roraima, Políticas Públicas setoriais, Metodologia da Pesquisa II (no $5^{\circ}$. Semestre para que os acadêmicos conciliassem com o Projeto de Pesquisa). Como optativas: Libras, Macuxi, Política de Direitos Sociais, Informática Básica, Redação. Essa como sugestão das egressas.

A docente entrevistada, relata que as disciplinas, componentes da nova matriz curricular, desenvolvem saberes mais generalizados, não oportunizando ao acadêmico uma vivência com a cultura local, já que Boa Vista está situada no extremo Norte do país, desafiando portanto um olhar diferenciado por seu multiculturalismo e seu plurilinguismo, além de sua particularidade fronteiriça com a República Bolivariana e com a Guyana Inglesa demandando uma série de expressões na problemática social e seu fluxo intercultural sinalado nas entrevistas; essas complexidades poderiam ser pautas de discussão e componentes de disciplinas optativas, para contemplar uma formação contextualizada com os saberes amazônicos.

Por isso, o objeto de estudo problematizado buscou criar um auto espelho para a academia debater sobre a região, disseminar entre os alunos a relevância da formação 
acadêmica sobre os aspectos e particularidades dessa cultura local, além de revisar o currículo periodicamente com via de uma implementação da cultura acadêmica, sugerimos.

\section{REFERÊNCIAS}

APPLE, Michael. Ideologia e Currículo. Ed. Brasiliense, Rio de Janeiro, 1989

BEUCHOT PUENTE, Maurício. Hermenéutica analógica y

educación.Universidad Iberoamericana Torreón. México,2007

de México,2012

Ordo Analogia e interpretacion y construcción del mundo.Universidad Autonoma

La hermenéutica em la Edad Media.Universidad Autonoma de México,2012

; VELASCO GÓMEZ, Ambrósio; VATTIMO,Gianni. Hermenéutica analógica y

Hermenéutica débil. Universidad Autonoma de México: México,2006.

BAYEN,Maurice. Historia de las universidades.,Tradução de A. Giralt Pont. colleción que sé? Oikos-tau, 1978

La hermenéutica y el ser humano.Paidós: México,2015

Actualidade de la hermenéutica analógica. Blanca Soares: México,2014

Tratato de hermenéutica analógica: Hacia um novo modelo de interpretación.

Universidad Autonoma de México: México,2015

Brasil, Lei n- 9.394 - 20 de dezembro de 1996. Estabelece as diretrizes e bases da educação nacional. Diário Oficial, Brasília, 23 de dezembro de 1996. Seção 1, p. 27.833-27.841.

BRASLAVSKY,Cecilia. Dez fatores para uma educação de qualidade para todos no século XXI. Fundación Santillana . Editora Moderna ,2004

BARREYRO, Gladys Beatriz. Mapa do Ensino Superior Privado. Brasília : Instituto Nacional de Estudos e Pesquisas Educacionais Anísio Teixeira, 2008.

CEVASCO, Maria Elisa. Dez lições sobre estudos culturais. Bom tempo editorial. 2 ed, São Paulo, 2008

BLAXTER,Loraine; HUGHES, Christina; TIGHT, Malcolm. Cómo se hace una investigación. Tradução: Gabriela Ventureira: Gedisa mexicana, 2004

GIL, Antônio Carlos. Como elaborar projetos de pesquisa - 5. Ed. - São Paulo: Atlas, 2010. 
LUCKESI, Cipriano Carlos et al. Fazer universidade: uma proposta metodológica. 12. Ed. São Paulo, Cortez:2001

MOREIRA, Antonio Flávio B.; SILVA, Tomaz Tadeu (Orgs.). Currículo, cultura e sociedade. 12 ed. São Paulo: Cortez, 2011.

MALINOWSKI, Bronislaw. Tradução do Gabinete Editorial de Edições. Uma teoria cientifica da cultura e outros ensaios. Edições 70. Portugal, 1976

OLIVE, Anabela Campos. Histórico da educação superior no Brasil in: Educação Superior no Brasil, SOARES, Maria Susana Amosa (Coord), Brasília: Coord. De Aperfeiçoamento de Pessoal de nível superior,2002, pág. 45.

SARDI, Dal Rosso(Org.). Ensino superior público e gratuidade. Atividades pagas em universidades gratuitas caminho para a privatização. ADUNB, Brasília: DF, 2002, pág. 15

SAMPIERI,Roberto Hernández;CALLADO,Carlos Férnandez; LUCIO,Maria del Pilar

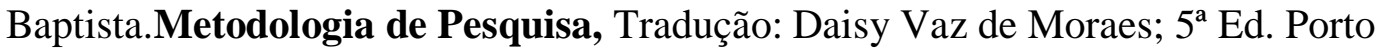
Alegre,Penso: 2013

SAVIANI, Nereide. Saber Escolar, currículo e didática: problemas da unidade conteúdo/método no processo pedagógico. 6.ed. revista - Campinas, SP: Autores Associados, 2010.

SEVERINO, Antônio Joaquim. Educação, Ideologia e contra Ideologia. Reimpr. 3. 23 ed. SAO PAULO: Cortez, 2007.

SILVA, Tomaz Tadeu da. Documentos de Identidade: uma introdução às teorias do currículo. 2a . Ed. Belo Horizonte: Autêntica, 2005.

PIMENTA, Selma Garrido; ANASTASIOU, Léa das Graças Camargos. Docência no Ensino Superior. (Coleção Docência em Formação) 4. Ed. São Paulo, Cortez: 2010. 